\title{
Navigating the Job Market for Careers Inside and Outside of Academia.
}

\author{
Benjamin Bammes ${ }^{1}$, Gabriella Kiss ${ }^{2}$, Paula Flicker ${ }^{3}$, Scott M. Stagg ${ }^{4}$ \\ 1. Direct Electron, LP, San Diego, CA, USA \\ 2. FEI, Hillsboro, OR, USA \\ 3. National Institute of General Medical Sciences, National Institutes of Health, Bethesda, MD, USA \\ 4. Institute of Molecular Biophysics, Department of Chemistry and Biochemistry, Florida State \\ University, Tallahassee, FL, USA
}

The instructors for this tutorial work in academia, industry, and government. Each of them will discuss their careers in science and the strategies that they used to secure essential training and employment. The format of the tutorial will include the speakers' individual experiences and conclude with a roundtable discussion.

Science is for curious individuals who want to know how things work and love the thrill of discovery. But how does one receive the education and training in a scientific discipline to prepare for a life long career? What are the milestones that need to be reached for embarking on a career in academia, industry, or government? What options are there for remaining at or moving away from the bench? There are several educational and training pathways one can take to develop as a scientist and a career path (Figure 1). During the course of the tutorial, each of these paths will be highlighted and examples presented for end-point career opportunities.

Some additional topics to be discussed will include:

- Should you go to graduate school for an M.S. or Ph.D.? How do you choose a graduate program? How do you select a mentor and a research laboratory to join?

- What are the benefits of the postdoctoral fellowship experience? Is a postdoctoral fellowship necessary for securing a job outside of academia?

- How to present yourself and your scientific training through your CV and cover letter.

- What are the career options at and away from the bench?

- How to make the most out of attending scientific conferences, including the art of networking. Should you attend career fairs?

- Tips for the successful interview.

- Finally, you have received a job offer! What additional information do you need from your future employer to make your decision? Now that you have secured your job, what opportunities are available for continuing education and career advancement? 


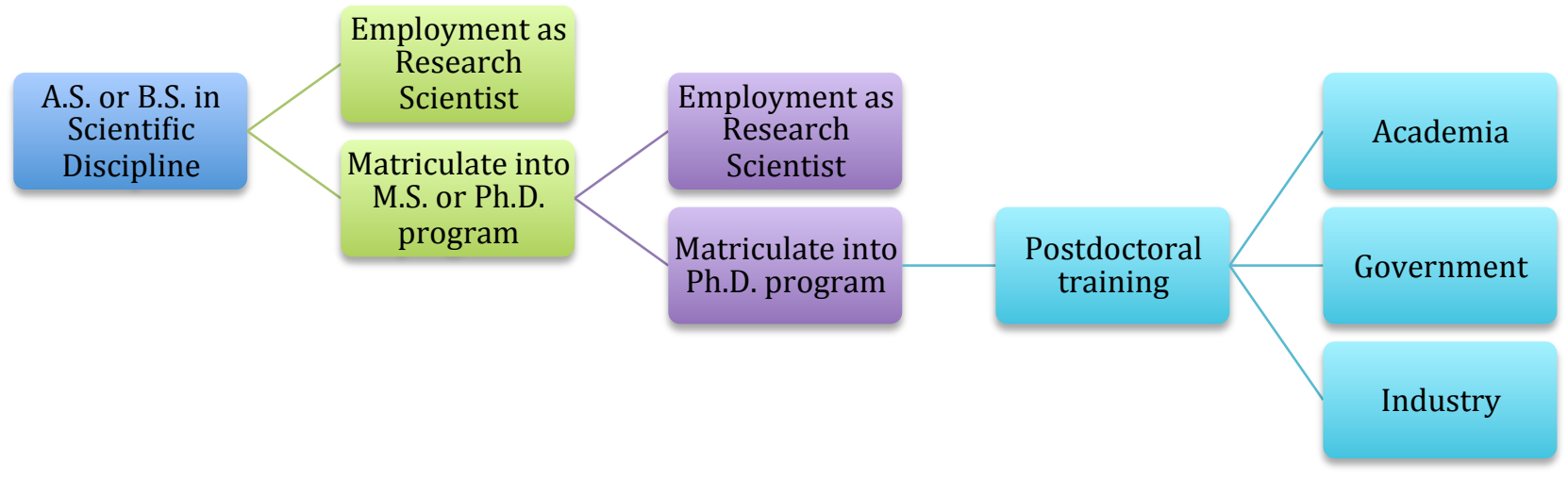

Figure 1. Flow chart for scientific career trajectories. 